\title{
Use of the Pendant Drop Method to Measure Interfacial Tension between Molten Polymers
}

\author{
Emerson Y. Arashiro, Nicole R. Demarquette \\ Departamento de Engenharia de Materiais \\ Escola Politécnica \\ Universidade de São Paulo \\ Av. Prof. Mello Moraes 2463, 05508-900 São Paulo - SP, Brazil \\ e-mail:nick@usp.br
}

Received: April 24, 1998; Revised: August 10, 1998

\begin{abstract}
In this paper the pendant drop method to measure interfacial tension between molten polymers is reviewed. A typical pendant drop apparatus is presented. The algorithms used to infer interfacial tension from the geometrical profile of the pendant drop are described in details, in particular a new routine to evaluate correctly the value of the radius at the apex of the drop, necessary to the calculation of interfacial tension is presented. The method was evaluated for the possibility of measuring the interfacial tension between polyethylene and polystyrene. It is shown that the method is unsuitable for the measurement of interfacial tension between high density polyethylene and polystyrene due possibly to a too small difference of density between the two polymers. Values of interfacial tension between low density polyethylene (LDPE) and polystyrene (PS) as a function of the molecular weight of PS are presented. It was shown that the interfacial tension between LDPE and PS increased as a function of molecular weight of PS up to values of molecular weight of roughly 40,000 g/mol, value for which entanglements occur.
\end{abstract}

Keywords: interfacial tension, polimer blends, pedant drop

\section{Introduction}

Polymer blends have gained an increasing popularity in the field of polymer science and industry during the last thirty years. The growth in the use of polymer blends is mainly because they combine the properties of different components to result in a material with optimized mechanical strength, low permeability to water and to oxygen, optical properties, low capital cost, single step processing and adaptability to recycling of reground products.

When working with polymer blends, it is important to obtain at least partial compatibility between the components of the product. Polymer compatibility is an important factor in the processing of polymer blends since it governs the adhesion and the condition of the interface and, therefore, the morphology and mechanical properties of the blend, i.e. the final characteristics of the blends. Interfacial tension is one of the key parameters that governs the compatibility between the components of the blend ${ }^{1,2}$. It is the single most accessible parameter that describes the thermodynamic state and structure of an interface.

Unfortunately, very few data are available regarding interfacial tension between pairs of polymers. Research has been limited in that field because there exist few methods that can be used to measure interfacial tension between molten polymers. Among the various methods to measure interfacial tension between two liquids, only a few are suitable for polymers because of their high viscosity. In general, the equilibrium static methods are most commonly used. They involve the evaluation of a profile of either a sessile drop ${ }^{3-11}$, or a spinning drop ${ }^{12-16}$ or a pendant drop ${ }^{17-27}$. Dynamic methods, based on the breaking thread and imbedded fiber were also used ${ }^{28-35}$ to determine interfacial tension. More recently, rheological theories have been developed to infer interfacial tension from small amplitude oscillatory shear measurements ${ }^{36-39}$. 
In this work the pendant drop method to measure interfacial tension between molten polymers is reviewed and an apparatus based on the pendant drop method is presented. The algorithms to infer interfacial tension from the pendant drop profile are described in details. The method was evaluated for the measurement of interfacial tension between polyethylene and polystyrene. The results are reported here.

\section{Theory of the Pendant Drop}

The pendant drop method is probably the most convenient, versatile and popular method to measure interfacial tension between molten polymers ${ }^{40,41}$. The pendant drop method involves the determination of the profile of a drop of one liquid suspended in another liquid at mechanical equilibrium. The profile of a drop of liquid suspended in another is determined by the balance between gravity and surface forces. The equation of Bashforth and Adams ${ }^{42}$ which is based on Laplace's equation, relates the drop profile to the interfacial tension through a nonlinear differential equation which is given below:

$$
\frac{1}{\frac{\mathrm{R}_{1}}{\mathrm{a}}}+\frac{\sin \phi}{\frac{\mathrm{x}}{\mathrm{a}}}=-\mathrm{B} \frac{\mathrm{z}}{\mathrm{a}}+2
$$

where $\mathrm{B}$ is given by

$$
\mathrm{B}=\frac{\mathrm{a}^{2} \mathrm{~g} \Delta \rho}{\gamma}
$$

where $\Delta \rho$ is the difference between the densities of the two polymers in contact, $g$ is the gravitational constant, $\gamma$ is the interfacial tension, $a$ is the radius of curvature at the apex of the drop, x, z, $\Phi$ are the coordinates defined as in Fig. 1,

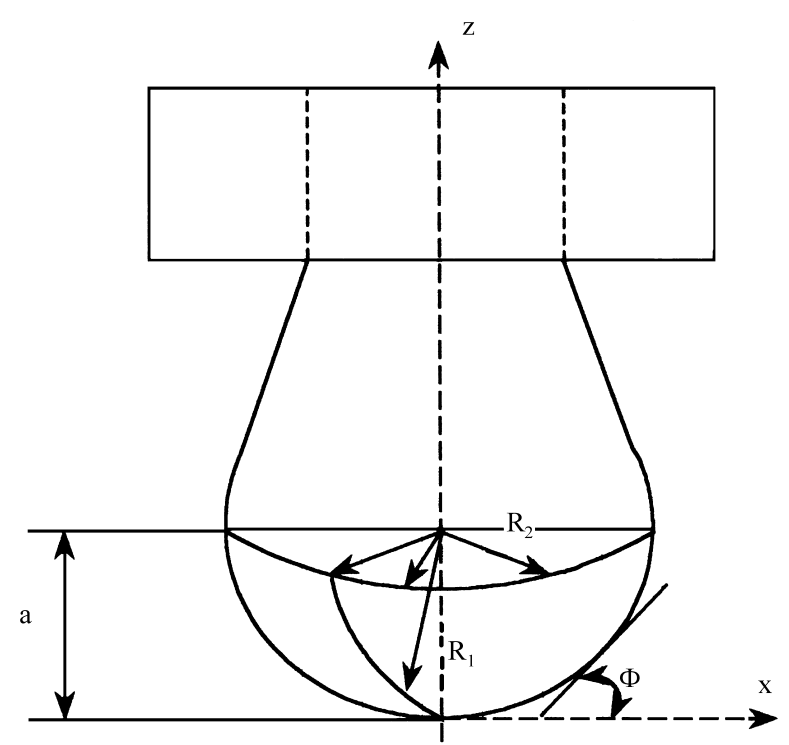

Figure 1. The pedant drop geometry. and $R_{1}$ is the radius of curvature at the point with coordinates $(\mathrm{x}, \mathrm{z})$.

$\mathrm{R}_{1}$ and $\Phi$ can be defined geometrically by:

$$
\begin{aligned}
& \mathrm{R}_{1}=\frac{\mathrm{ds}}{\mathrm{d} \phi}=\frac{\left[1+\left(\frac{\mathrm{dz}}{\mathrm{dx}}\right)^{2}\right]^{3 / 2}}{\frac{\mathrm{d}^{2} \mathrm{z}}{\mathrm{dx}^{2}}} \\
& \sin \phi=\frac{\frac{\mathrm{dz}}{\mathrm{dx}}}{\left[1+\left(\frac{\mathrm{dz}}{\mathrm{dx}}\right)^{2}\right]^{1 / 2}}
\end{aligned}
$$

\section{Evolution of the Method}

In 1882, Bashforth and Adams derived the theoretical form of a pendant drop and calculated tables of drop contours. These tables can be used to determine the interfacial tension by fitting the experimentally measured drop contour to the theoretical curve. Photographs of the evolving drop could be taken as a function of time for comparison. However, this procedure is very tedious. To simplify this procedure, the following empirical relationship was proposed by Andreas ${ }^{43}$ :

$$
\gamma=\frac{\mathrm{g} \mathrm{D}_{\mathrm{e}}^{2} \Delta \rho}{\mathrm{H}}
$$

where $\gamma$ is the interfacial tension, $\Delta \rho$ is the density difference, $\mathrm{D}_{\mathrm{e}}$ is the equatorial diameter of the drop, $\mathrm{H}$ is a correction factor which is related to the shape factor of the pendant drop, $\mathrm{S}$, defined as:

$$
\mathrm{S}=\frac{\mathrm{D}_{\mathrm{s}}}{\mathrm{D}_{\mathrm{e}}}
$$

where $D_{s}$ is the drop diameter measured horizontally at a distance $D_{e}$ away from the apex of the drop. Stauffer ${ }^{44}$ and Fordham $^{45}$ obtained the values of $\mathrm{H}$ by solving the Bashforth and Adams equation. The above techniques have been discussed by Adamson ${ }^{46}$. A more elaborate method was proposed by Roe et $a l .{ }^{40}$ It involves a series of $S$ values, $\mathrm{S}_{\mathrm{n}}$, where:

$$
S_{n}=\frac{D_{n}}{D_{e}}
$$

where $D_{n}$ is the horizontal drop diameter measured at a distance $D_{e} \times n / 10$, (with $n$ being an integer $1 \leq n \leq 10$ ) from the apex of the drop.

Unfortunately, the above methods use only few measurements to define the entire shape of the drop, leading to imprecision in the comparison between the experimental profile and the numerical solution of the Bashforth and Adams equation. The error involved in using these methods was analyzed by $\operatorname{Roe}^{40}$. Another problem encountered in 
using the above methods of comparison is in the determination of the time at which the mechanical equilibrium of the drop is reached. As an example, $\mathrm{Wu}^{47}$ recommends that the variation of $1 / \mathrm{H}$ in Eq. (5) should be less than $0.5 \%$ over a period of fifteen minutes.

Recent progress in image analysis and data acquisition systems has made it possible to obtain a direct digitization of the drop image with the aid of a video frame grabber of digital camera ${ }^{48,49}$. The digital signals are analyzed using different algorithms to determine the interfacial tension from the drop profile $\mathrm{e}^{21,24,50-55}$.

Anastasiadis ${ }^{21}$ developed an algorithm that uses a shape comparison first developed by Siegel ${ }^{56,57}$ (used in the comparison of the shape of primates and human skulls). These routines are resistant to outlying points that may be encountered in case of noisy digitized signals. The programs showed satisfactory performance in the evaluation of the interfacial tension of polymers. Similar algorithms were used by Demarquette and $\mathrm{Kamal}^{24}$.

A typical pendant drop apparatus is described below. This equipment was constructed at the Metallurgical and Materials Engineering Department of the University of São Paulo. The drop analysis of experiments conducted in this work was conducted using algorithms based on the ones developed by Demarquette and $\mathrm{Kamal}^{24}$ but differ in the evaluation of geometric parameters of the drop (particularly in the evaluation of the radius of curvature of the drop at the apex).

\section{Description of a Typical Apparatus}

\subsection{General description}

A typical pendant drop apparatus consists of three parts: an experimental cell a illuminating and a viewing system to visualize the drop and a data acquisition system to infer the interfacial tension from the pendant drop profile. The apparatus which was developed at the Metallurgical and Materials Engineering Department of the University of São Paulo was similar to the one described in more details in Ref. 25.

Figure 2 shows a sketch of the apparatus.

\subsection{Description of the software}

Using a pendant drop system it is possible to register the evolution of a drop of one molten polymer into another as a function of time. Images of the drop are taken automatically at a certain frequency which depends on the time duration of the test. The images are digitized by a frame grabber resident in the computer and are analyzed on line measuring, therefore, the interfacial tension "on line" during the experiment. The contours of the drops are analyzed to infer interfacial tension from the profile of the drop using different programs. The whole process of digitalization and analysis of the drop lasts less than 40 seconds. It consists of four steps: 1) capture and digitalization of the image of

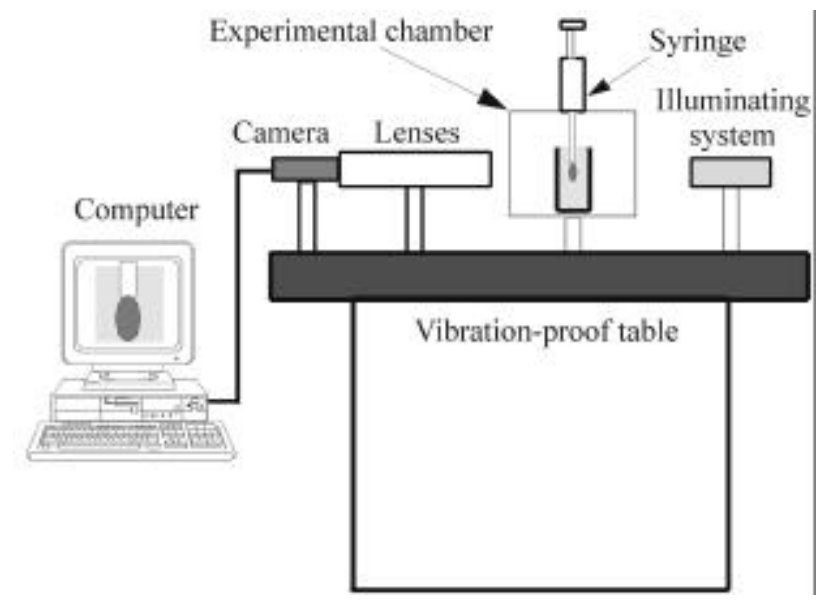

Figure 2. Pendant drop apparatus.

the pendant drop; 2) extraction of the drop contour, determination of the radius of curvature at the apex necessary for the calculation of interfacial tension; 3) smoothing of the extracted contour of the drop using polynomial regression; 4) shape comparison between the theoretical and experimental drop, inferring the interfacial tension value. These four steps are described below.

1) Capture and digitalization of the image of the pendant drop

The drop is captured by the frame grabber with a resolution of $480 \times 640$ using tools of a commercial software.

2) Extraction of the contour and determination of the radius of curvature at the apex necessary for the calculation of interfacial tension

An edge detection program is used after the digitization of the image of the drop to obtain its contour. The contour of the drop is defined by the last pixel with a gray level higher than the threshold value. Some researchers ${ }^{48}$ have shown that the interfacial tension value is affected by less than $1 \%$ if the contour of the drop is chosen based on the last black (above the threshold) instead of the first white (below the threshold) pixel.

In order to evaluate the interfacial tension using Eq. (2) it is necessary to know the radius of curvature at the apex of the drop. In this work a special routine was written in order to evaluate this parameter. In many works, the value of the radius of curvature at the apex of the drop is taken as the distance between the apex and the center of the diameter as shown in Fig. 3a. In the case of longer drops as shown in Fig. $3 b$ the values of the radius at the apex are overestimated, consequently overestimating the values of interfacial tension (see Eq. (2)).

Once the edge detection has been performed, the symmetry axis of the drop is determined. The intersection $\mathrm{I}\left(\mathrm{X}_{\mathrm{I}}\right.$, $\mathrm{Y}_{\mathrm{I}}$ ) between the drop profile and the symmetry axis is also 

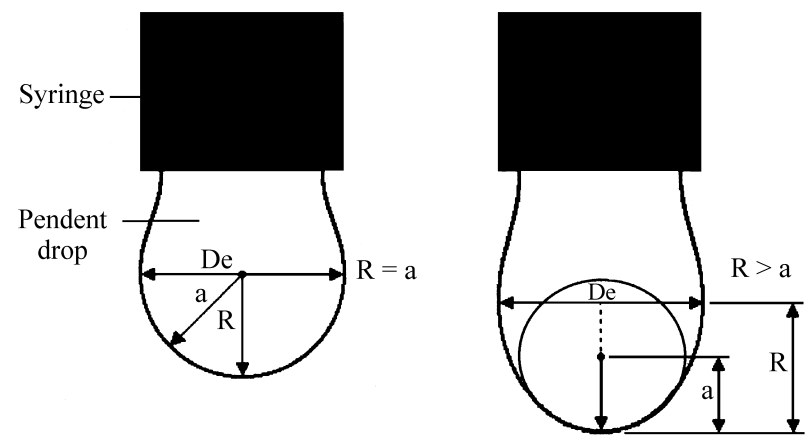

Figure 3. Evaluation of the radius of curvature at the apex of a pendant drop.

determined. Circles of different radiuses are superposed to the maximum number of points around the apex. The radius of the circle that superposes to the maximum number of points is taken equal as the radius of curvature of the drop at the apex.

\section{3) Smoothing of the drop}

A smoothing program is needed due to the finite resolution of the frame grabber. The smoothing routine makes use of local polynomial regression methods. The smoothing is done piece wise (i.e. point by point replacement) along the whole profile of the drop. The program starts by identifying $\mathrm{n}$ contiguous points along the drop profile. The program iterates the smoothing loop by operation on the first $\mathrm{n}$ points. The angle $\omega$ made by those $\mathrm{n}$ points with the horizontal axis is determined by a linear least square regression. The middle point is rotated and translated according to the transformation below:

$$
\begin{aligned}
& x^{\prime}=\left(x-x_{m}\right) \cos \omega+\left(y-y_{m}\right) \sin \omega \\
& y^{\prime}=\left(y-y_{m}\right) \cos \omega-\left(x-x_{m}\right) \sin \omega
\end{aligned}
$$

where (x', y') are the coordinates of the points in the second coordinate system, $(\mathrm{x}, \mathrm{y})$ are the coordinates of the points in the first coordinate system, $\left(\mathrm{x}_{\mathrm{m}}, \mathrm{ym}_{\mathrm{m}}\right)$ are the coordinates of the middle point in the first coordinate system.

The points are then smoothed in the new coordinate system. After smoothing the coordinates of the midpoint in the first coordinate system are given by:

$$
\begin{aligned}
& \mathrm{xs}_{\mathrm{m}}=\mathrm{x}_{\mathrm{sm}} " \cos \omega-\mathrm{y}_{\mathrm{cm}} " \sin \omega+\mathrm{x}_{\mathrm{m}} \\
& \mathrm{ys}_{\mathrm{m}}=\mathrm{x}_{\mathrm{sm}} " \sin \omega+\mathrm{y}_{\mathrm{cm}} " \cos \omega+\mathrm{y}_{\mathrm{m}}
\end{aligned}
$$

where $\left(\mathrm{x}_{\mathrm{sm}}, \mathrm{y}_{\mathrm{sm}}\right)$ are the coordinates of the midpoint after smoothing in the first coordinate system, ( $\left.x^{\prime}{ }_{s m}, y^{\prime}{ }_{s m}\right)$ are the coordinates of the midpoint after smoothing in the second coordinate system, $\left(\mathrm{x}_{\mathrm{m}}, \mathrm{y}_{\mathrm{m}}\right)$ are the coordinates of the midpoint before smoothing in the first coordinate system.

Each iteration produces, the smoothed value for the midpoint of the target group. Therefore, the first $n / 2$ and last $n / 2$ points of the drop are not smoothed.
The method and algorithm were first used by Anastasiadis et al. ${ }^{21}$.

\section{4) Shape Comparison}

This program makes a comparison of the shapes using the experimental points after smoothing and the theoretical points found by solving the Bashforth and Adams equation by a fourth order Runge-Kunta method. The Bashforth and Adams equation is first solved for a value of B (Eq. 2) approximated by the empirical formula of Huh and Reed ${ }^{38}$. The empirical formula of Huh and Reed is based on the following equation:

$$
\mathrm{B}=\left[\mathrm{e}^{\left(-6.70905+15.30025 \mathrm{~S}-16.44709 \mathrm{~S}^{2}+9.92425 \mathrm{~S}^{3}-2.585035 \mathrm{~S}^{4}\right)}\right]^{1 / 2}
$$

where $\mathrm{S}$ is the ratio De/Ds, De is the equatorial diameter of the drop, Ds is the diameter measured horizontally at a distance De from the apex of the drop.

A robust shape comparison between the experimental and the theoretical profiles is then performed. The robust shape comparison consists of an optimization on five parameters: three parameters for alignment of the imaging system to the coordinate system of the dimensionless drop (an $\mathrm{x}$ translation, a $\mathrm{x}$ translation and a rotation), one parameter for the magnification factor of the drop and one parameter for the scaling factor $\mathrm{B}$. The optimal value is then obtained, and the interfacial tension is calculated from the Eq. (2).

More details about the calculations used to perform the shape comparison can be found in Siegel ${ }^{56,57}$ who first used this method for the shape comparison of skulls of primates.

\section{Use of the Method to Measure Interfacial Tension between Polyethylene and Polystyrene}

\subsection{Material and material characterization}

Pure monodisperse polystyrene of different molecular weight and low and high density polyethylene were used in this work to evaluate the pendant drop as a method to measure the interfacial tension between polymers.

Table 1 shows the materials used in this study; the molecular weight of the polystyrene samples reported were obtained from Sigma Aldrich and the molecular weight of the polyethylene samples were measured by G.P.C. at Polisul.

In order to evaluate the interfacial tension between two polymers using the pendant drop method it is necessary to evaluate the density of the polymers in the molten state. Unfortunatelly, it is very difficult to measure density of polymers in the molten stage ${ }^{59}$. In this work the densities of polyethylene samples were evaluated using Tait Equation $^{60}$; the densities of polystyrene were obtained using the empirical equation of state of Fox and Flory ${ }^{61}$ as follows. 
Table 1. Materials used in this study.

\begin{tabular}{lcccc}
\hline Material & \multicolumn{2}{c}{ Molecular weight } & Supplier \\
\cline { 2 - 4 } & $\mathrm{M}_{\mathrm{n}}(\mathrm{g} / \mathrm{mol})$ & Polydispersive Index & $\mathrm{d}\left(\mathrm{g} / \mathrm{cm}^{3}\right)$ & Aldrich Chemicals \\
\hline Light density Polyethylene & 17.600 & 9 & 0.80 & Aldrich Chemicals \\
Low density Polyethylene & 20.200 & 4 & 0.76 & Aldrich Chemicals \\
Polystyrene PS & 14.000 & 1.06 & 0.96 & Aldrich Chemicals \\
Polystyrene PS & 18.000 & 1.07 & 0.96 & Aldrich Chemicals \\
Polystyrene PS 3 & 29.000 & 1.05 & 0.96 & Aldrich Chemicals \\
Polystyrene PS & 1.07 & 1.04 & 0.96 & Aldrich Chemicals \\
Polystyrene PS & 108.000 & 1.11 & 0.97 & Aldrich Chemicals \\
Polystyrene PS & 200.000 & 1.16 & 0.97 & Aldrich Chemicals \\
Polystyrene PS & 340.000 & & 0.97 &
\end{tabular}

According to Tait Equation ${ }^{60}$ the specific volume of a polymer as a function of temperature and pressure can be written as:

$$
\mathrm{V}(\mathrm{T}, \mathrm{P})=\mathrm{V}(0, \mathrm{~T})\left[1-0.0894 \ln \left(1+\frac{\mathrm{P}}{\mathrm{B}}(\mathrm{T})\right)\right]
$$

where $\mathrm{V}(0, \mathrm{~T})$ and $\mathrm{B}(\mathrm{T})$ are the Tait Equation parameters and are respectively the specific volume as zero pressure and afunction of temperature and $\mathrm{P}$ is the pressure.

Using PVT (Pressure Volume Temperature) data it is possible to infer the Tait Equation parameters $\mathrm{B}(\mathrm{T})$ and $\mathrm{V}(0, \mathrm{~T})$. In this work the Tait Equation parameters used wer er espectively:

ForLDPE $^{62}$

$$
\begin{aligned}
& \mathrm{B}=1929 \mathrm{e}^{-4.70 \times 10^{-3} \mathrm{~T}} \\
& \mathrm{~V}(0, \mathrm{~T})=1.14 \mathrm{e}^{6.95 \times 10^{-4} \mathrm{~T}}
\end{aligned}
$$

For HDPE ${ }^{63}$

$$
\begin{aligned}
& B=1799 e^{-4.739 \times 10^{-3} \mathrm{~T}} \\
& \mathrm{~V}(0, \mathrm{~T})=1.1595 \mathrm{e}^{8.0394 \times 10^{-4} \mathrm{~T}}
\end{aligned}
$$

where $\mathrm{T}$ is the temperature in ${ }^{\circ} \mathrm{C}$.

These parameters were chosen because they were inferred from PVT data of polymers with similar molecular weights as the ones used in this work. In both works ${ }^{62}$ and $^{63}$ the authors showed that their experimental data and the equation of state give the same results to within 0.001 $\mathrm{g} / \mathrm{cm}^{3}$.

The density of polystyrene was not evaluated using Tait Equation because no Tait parameters for polystyrene as a function of molecular weight has been published up to date. Instead, the values of the density of polystyrene were taken from an empirical equation of State proposed by Fox and Flory $^{61}$. Their equation was obtained for molecular weight between 3,000 and 85,000. The equation of state taken for the density as a function of temperature in this work were:

$$
\begin{array}{ll}
\text { If } \mathrm{M}_{\mathrm{n}}<50,000 & \mathrm{~d}=1.10-0.00069 \mathrm{~T} \\
\text { If } \mathrm{M}_{\mathrm{n}}>50,000 & \mathrm{~d}=1.10-0.00068 \mathrm{~T}
\end{array}
$$

Fox and Flory reported a difference between the prediction of the proposed equation and the experimental data of less than $0.03 \%$.

\subsection{Evaluation of the pendant drop method to measure interfacial tension between polyethylene and polystyrene}

Figure 4 shows the typical processing sequence for a drop of polymer. It this case it is shown a drop of polystyrene $\left(M_{n}=200,000 \mathrm{~g} / \mathrm{mol}\right)$ inside a matrix of Low Density Polyethylene at a temperature of $202{ }^{\circ} \mathrm{C}$. Figure 4 a shows the drop after digitalization as it appears on the screen, Figure $4 \mathrm{~b}$ shows the edge detection, Fig. 4c shows the experimental contour after smoothing and Fig. 4d shows the superposition of the theoretical contour inferred from the shape comparison and the experimental contour. It can be seen from Fig. 4d the good agreement between the experimental and theoretical contour.

Figure 5 shows the evolution of the contour of a drop of polystyrene $\left(\mathrm{M}_{\mathrm{n}}=200,000 \mathrm{~g} / \mathrm{mol}\right)$ inside a matrix of low density polyethylene at a temperature of $202{ }^{\circ} \mathrm{C}$ at different times (at the beginning of the experiment and after 1, 2, 3, $4,5,6,10,12 \mathrm{~h}$ ) during the experiment. Figure 6 shows the interfacial tension calculated from the shape comparison as a function of time for the same drop. It can be seen from Fig. 5 that after $10 \mathrm{~h}$ the contour of the drop does not evolve any more. It can be seen from Fig. 6 that the value of interfacial tension is constant after $10 \mathrm{~h}$. Typically, it takes eight to ten hours for a drop of polystyrene in a matrix of low density polyethylene to reach equilibrium. The time to reach mechanical equilibrium depends on the viscosity of the samples involved in the measurement, i.e. on the tem- 

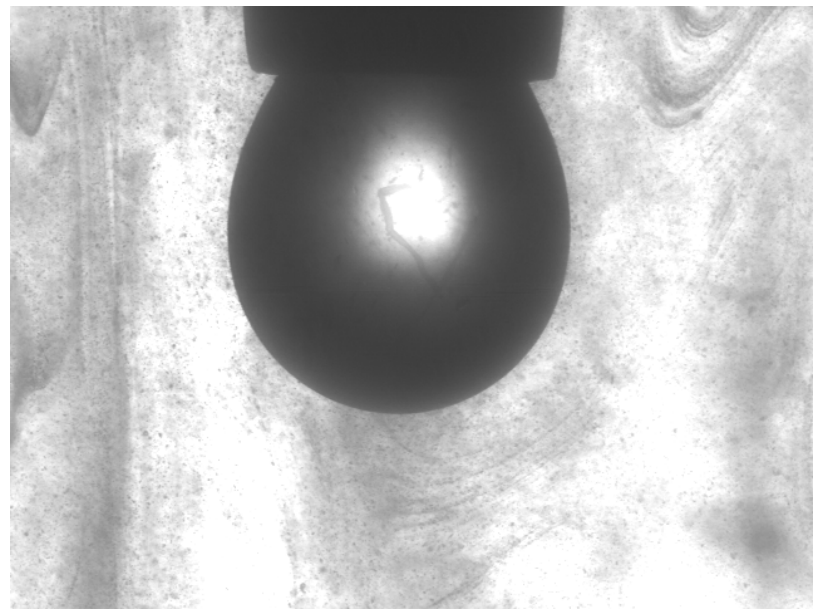

Figure 4a. Digitized drop.

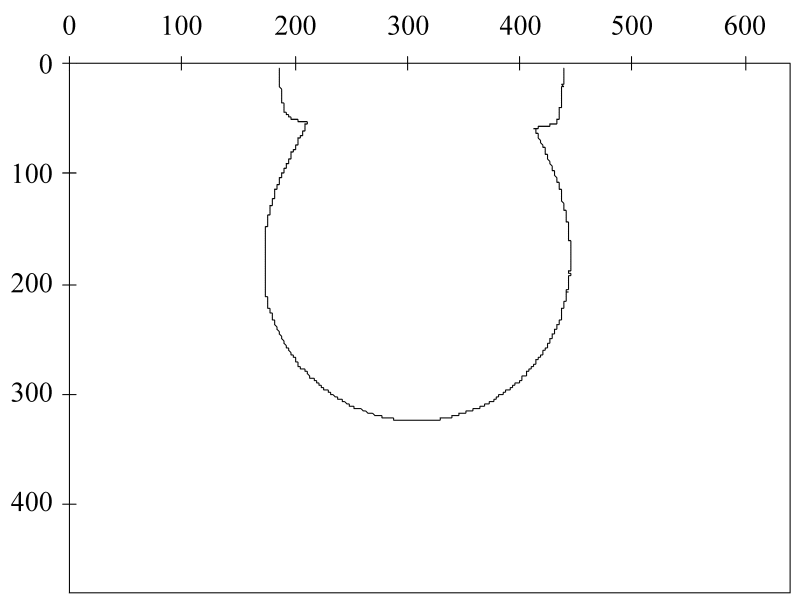

Figure 4b. Edge detection

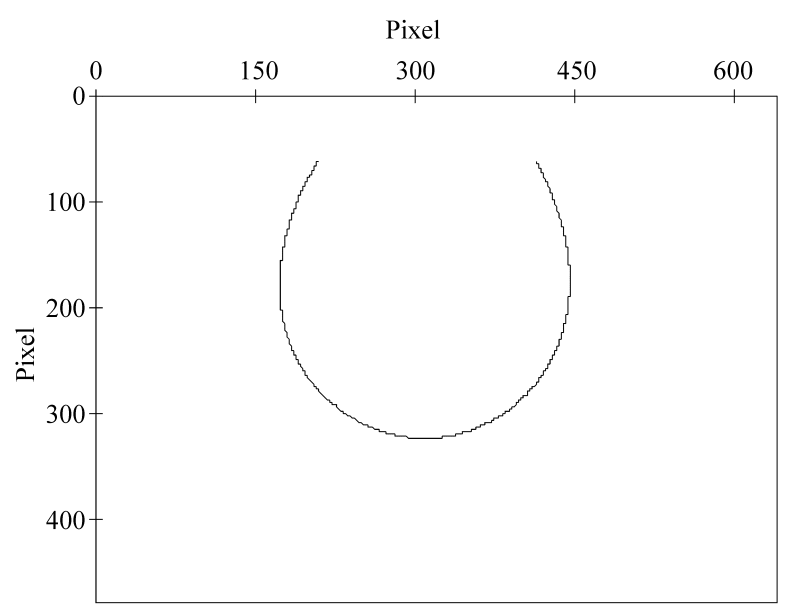

Figure 4c. Smoothed profile.

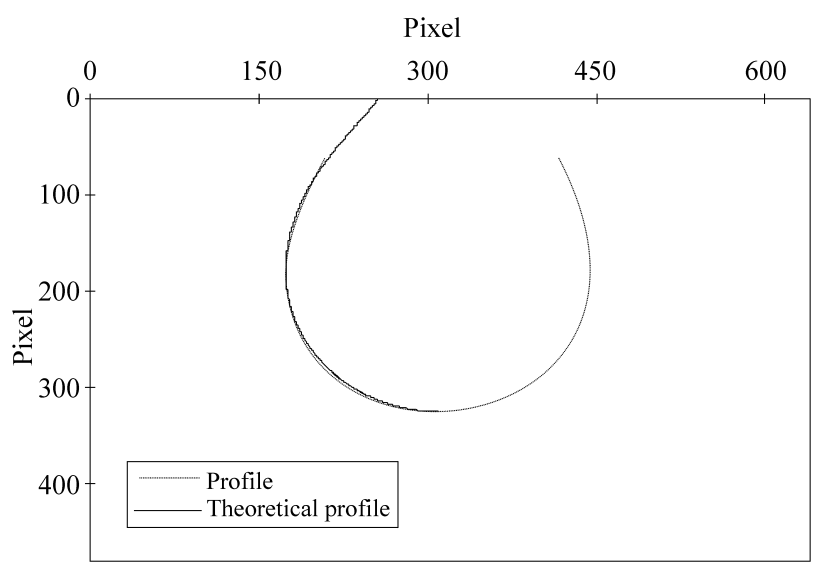

Figure 4d. Superposition of the experimental profile and theoretical profile.

Figure 4. Pendant drop of polystyrene $(\mathrm{Mn}=200,000 \mathrm{~g} / \mathrm{mol})$ in low density polyethylene at $202{ }^{\circ} \mathrm{C}$.

perature at which the experiment is performed and also on the molecular weight of the sample.

It was verified monitoring the molecular weight before and after the experiment that no thermal degradation occurred. Table 3 presents the values of molecular weight before and after an interfacial tension measurement measured by G.P.C of one sample of polystyrene. It can be seen that the molecular weight of the polystyrene did not change during the experiment. Also, if any degradation of the polymer would have occurred it would had affected the value of interfacial tension and the curve $\gamma=f(t)$ would not be constant.

It can be seen that the evolution of the interfacial tension $\gamma(\mathrm{t})$, obtained experimentally from the shape comparison, as a function of time can be fitted by an exponential decay as follows:

$$
\gamma(\mathrm{t})-\gamma_{\infty}=\left(\gamma_{0}-\gamma_{\infty}\right) \mathrm{e}^{-\mathrm{m}\left(\mathrm{t}-\mathrm{t}_{0}\right)}
$$

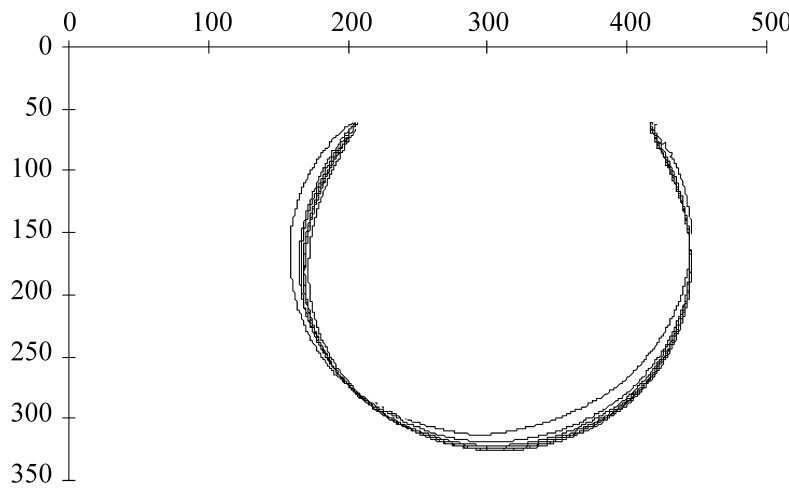

Figure 5. Evolution of the profile of a drop of polystyrene ( $\mathrm{Mn}=200,000$ $\mathrm{g} / \mathrm{mol}$ ) in low density polyethylene at $202{ }^{\circ} \mathrm{C}$.

where $\gamma(\mathrm{t})$ is the value obtained experimentally from the shape comparison as a function of time, $\gamma_{\infty}$ is the value of $\gamma(\mathrm{t})$ at infinite time, i.e. the value of interfacial tension, $\gamma_{0}$ is the value of $\gamma(\mathrm{t})$ a $\mathrm{t}=0$ and $\mathrm{m}$ a constant. These results suggest the possibility of inferring interfacial tension from 
Table 2. Molecular weight of a the polystyrene before and after the experiment.

\begin{tabular}{lcccc}
\hline Polymer & \multicolumn{2}{c}{$\begin{array}{c}\text { Molecular weight before interfacial tension } \\
\text { measurement }\end{array}$} & \multicolumn{2}{c}{$\begin{array}{c}\text { Molecular weight after interfacial tension } \\
\text { measurement }\end{array}$} \\
\cline { 2 - 5 } & $\mathrm{M}_{\mathrm{n}}(\mathrm{g} / \mathrm{mol})$ & $\mathrm{I}$ & $\mathrm{M}_{\mathrm{n}}(\mathrm{g} / \mathrm{mol})$ & $\mathrm{I}$ \\
\hline Polystyrene PS & 213.000 & 1.04 & 210.000 & 1.04 \\
\hline
\end{tabular}

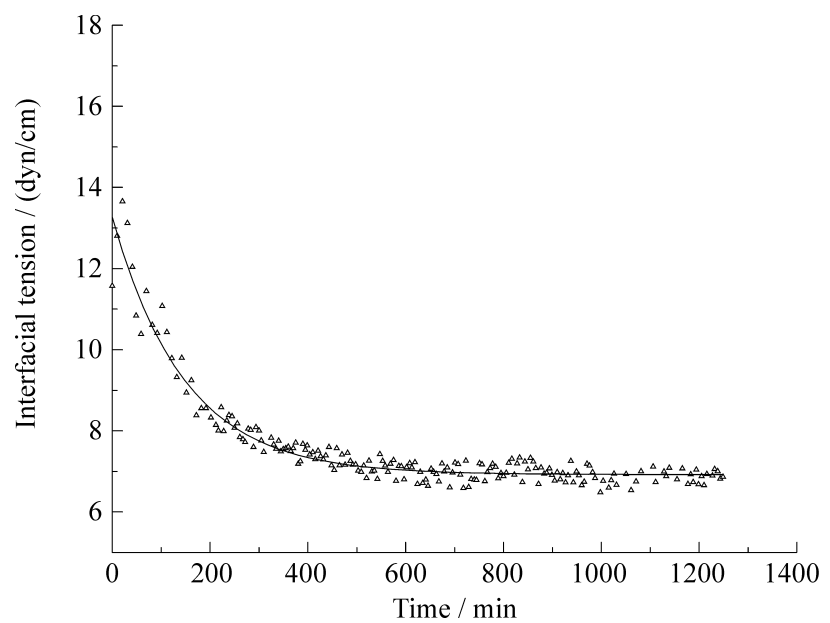

Figure 6. $\gamma(\mathrm{t})$ between polystyrene $(\mathrm{Mn}=200,000 \mathrm{~g} / \mathrm{mol})$ and low density polyethylene at $202{ }^{\circ} \mathrm{C}$.

transient measurement and thus shortening the duration of the experiment.

Figure 7 shows the evolution of a pendant drop of PS $\left(\mathrm{M}_{\mathrm{n}}=200,000 \mathrm{~g} / \mathrm{mol}\right)$ in LDPE at a temperature of $202{ }^{\circ} \mathrm{C}$ at the beginning of the experiment, after 30,60, 120, 300 and $720 \mathrm{~min}$. It can be seen that the drop is moving upwards and that it is impossible to obtain the pendant drop. This is probably due to the too small difference of density between the two polymers in the molten state. Therefore it was not possible to infer interfacial tension between HDPE and PS using the pendant drop method.

\subsection{Influence of molecular weight of PS on interfacial tension between LDPE and PS}

Figure 8 shows the interfacial tension between LPDE and PS as a function of molecular weight of PS at a temperature of $202{ }^{\circ} \mathrm{C}$. The experimental values are reported in Table 3. During experiments, measurements were taken every five minute, until the mechanical equilibrium of the drop was reached. The mechanical equilibrium was determined when four consecutive measurements of interfacial tension from the drop profile varied by less than $2 \%$. Thereafter, measurements were taken every five minute for two hours; the data were averaged and reported as the equilibrium interfacial tension value. The values reported in Table 3 are the average values of interfacial tension from the analysis of two to four drops.

The polydispersity of the samples of PS used here ranged from 1.05 to 1.16 . It has been shown that the polydispersityaffects the interfacialtensionbetween polymers ${ }^{64}$, but the difference of polydispersity of the samples studied here is not high enough to have any effect on the interfacial tension. It can be seen from Fig. 8 that the interfacial tension increases as the molecular weight of polystyrene increases, as expected thermodynamically. The experimental data appear to suggest that the interfacial tension between LPDE and PS starts to level off when the molecular weight of PS exceeds 30,000 $\mathrm{g} / \mathrm{mol}$. This value of $30,000 \mathrm{~g} / \mathrm{mol}$ corresponds to the value at which entanglements start to occur for $\mathrm{PS}^{35}$. Kamal et $a l .{ }^{25}$ and Elingson et al. ${ }^{31}$ observed the same trend for the interfacial tension between polypropylene and polystyrene and polymethylmethacrylate and polystyrene respectively when the molecular weight of polystyrene was varied.

\section{Conclusion}

In this paper the pendant drop method was reviewed for measuring interfacial tension between molten polymers. The pendant drop method consists of inferring the interfacial tension from the shape profile of a pendant drop of one liquid in another at mechanical equilibrium. At the beginning of the sixties, when this method started to be used to measure interfacial tension between molten polymers, photographs of the evolving drop were taken as a function of time and geometrical parameters of those drops were compared to tabulated values in order to infer interfacial tension. These procedures were very tedious and not precise. Nowadays, thanks to progress in data acquisition and drop profile analysis, it is possible to couple the pendant drop method to a data acquisition system and infer the interfacial tension from the analysis of the image of the drop.

In this work a typical pendant drop apparatus was presented and the algorithms used to infer the interfacial tension from the drop profile were described in details. The whole process consisted of four steps: 1) capture and digitalization of the image of the pendant drop; 2) extraction of the drop contour, determination of the radius of curvature at the apex necessary for the calculation of interfacial tension; 3) smoothing of the extracted contour of the drop using polynomial regression; 4) shape comparison between the theoretical and experimental drop, inferring the interfacial tension value. It was necessary to write a small routine in order to evaluate correctly the value of the radius of curvature of the drop at the apex. 


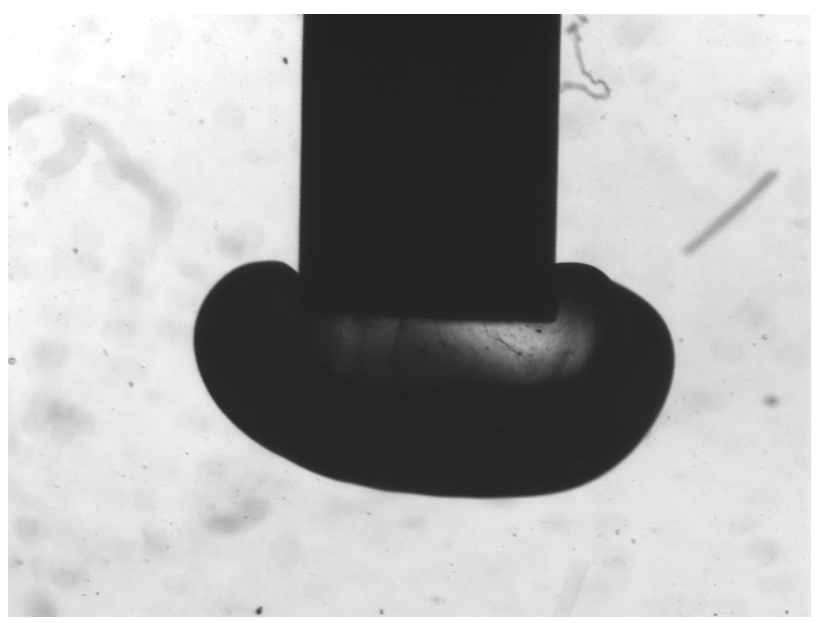

Figure 7a. Drop of PS $(200,000 \mathrm{~g} / \mathrm{mol})$ in $\operatorname{HDPE}(\mathrm{t}=0)$ at $202^{\circ} \mathrm{C}$.

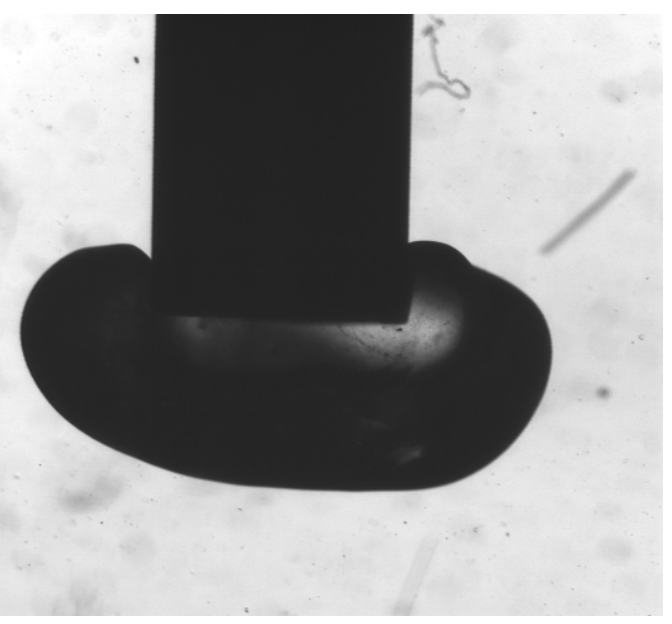

Figure 7b. Drop of PS $(200,000 \mathrm{~g} / \mathrm{mol})$ in $\operatorname{HDPE}(\mathrm{t}=20 \mathrm{~min})$ at $202^{\circ} \mathrm{C}$

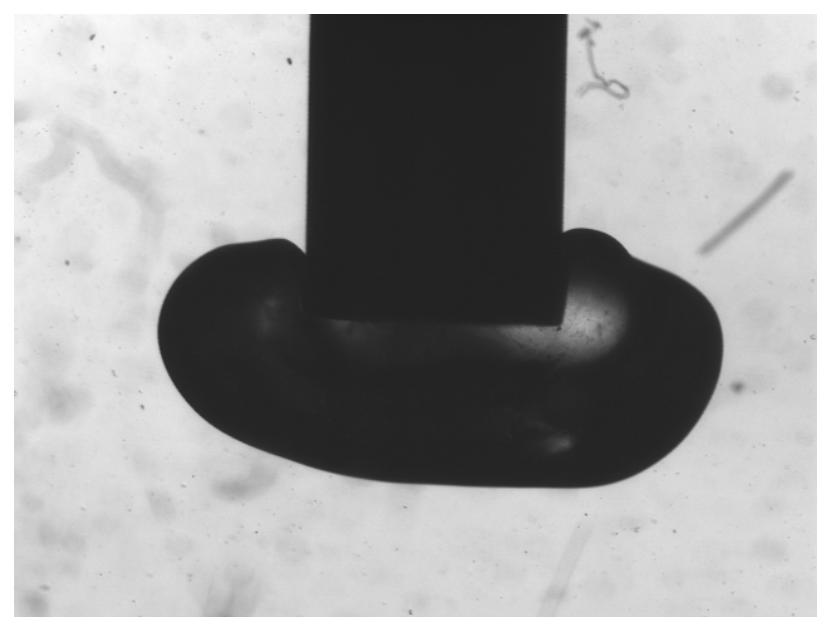

Figure 7c. Drop of PS $(200,000 \mathrm{~g} / \mathrm{mol})$ in $\operatorname{HDPE}(\mathrm{t}=60 \mathrm{~min})$ at $202{ }^{\circ} \mathrm{C}$.

Figure 7. Evolution of a pendant drop of PS $\left(M_{n}=200,000 \mathrm{~g} / \mathrm{mol}\right)$ in HDPE at $202{ }^{\circ} \mathrm{C}$

The method was tested to measure interfacial tension between polyethylene and polystyrene. It was shown that it was not possible to measure interfacial tension between

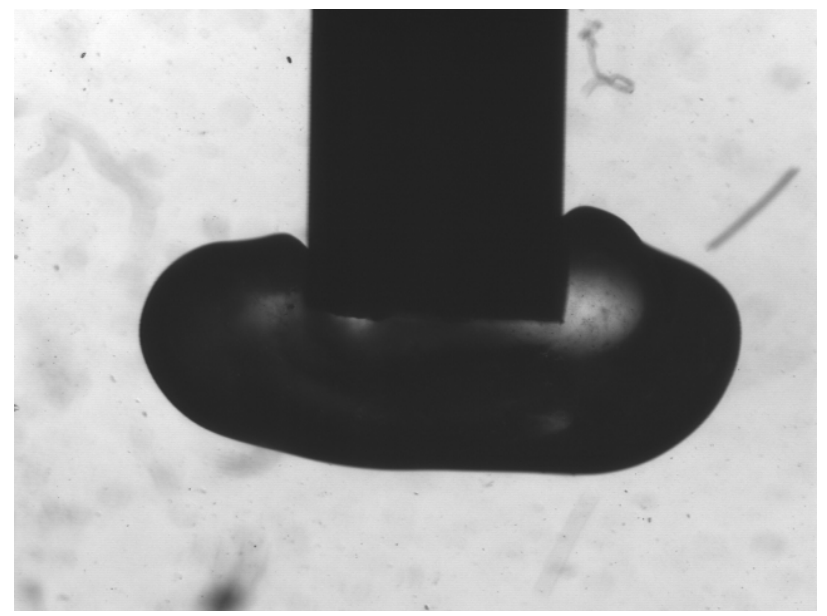

Figure 7d. Drop of PS $(200,000 \mathrm{~g} / \mathrm{mol})$ in HDPE $(\mathrm{t}=300 \mathrm{~min})$ at $202^{\circ} \mathrm{C}$.

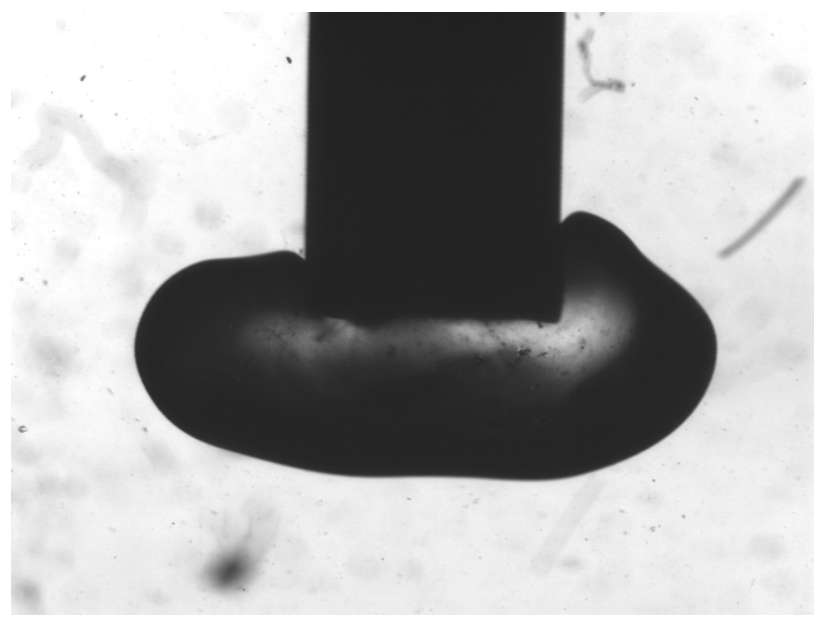

Figure 7e. Drop of PS $(200,000 \mathrm{~g} / \mathrm{mol})$ in $\operatorname{HDPE}(\mathrm{t}=720 \mathrm{~min})$ at $202^{\circ} \mathrm{C}$.

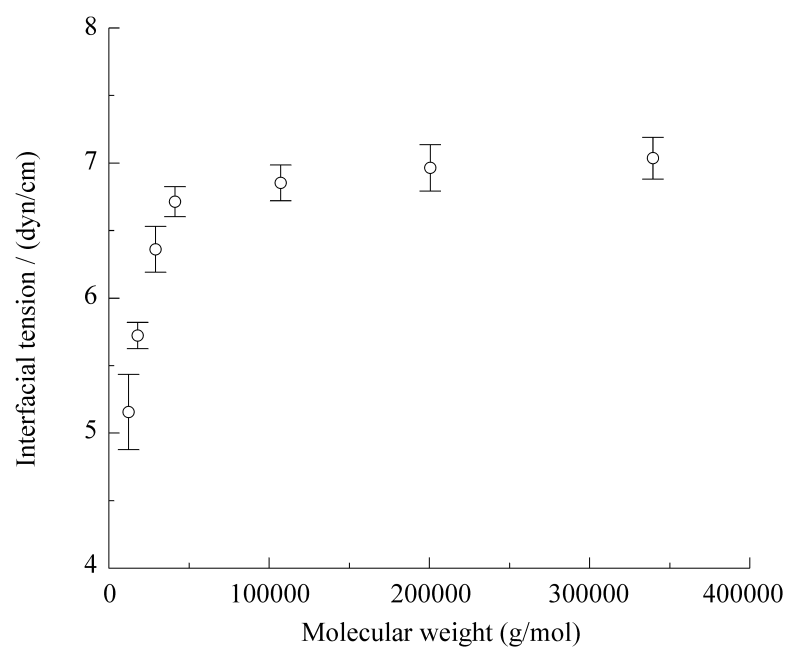

Figure 8. Interfacial tension between low density polyethylene and polystyrene as a function of molecular weight of polystyrene.

high density polyethylene and polystyrene using the pendant drop method most likely because the density difference between the two polymers is too low. However, it was possible using the pendant drop method to measure inter- 
Table 3. Interfacial tension results at $202{ }^{\circ} \mathrm{C}$.

\begin{tabular}{lcc}
\hline Polymer pair & $\begin{array}{c}\text { PS molecular } \\
\text { weight }(\mathrm{g} / \mathrm{mol})\end{array}$ & $\begin{array}{c}\text { Interfacial tension } \\
(\text { dyn/cm })\end{array}$ \\
\hline LPDE/PS $_{1}$ & 14,000 & $5.2 \pm 0.2$ \\
LPDE/PS $_{2}$ & 18,000 & $5.9 \pm 0.1$ \\
LPDE/PS $_{3}$ & 29,000 & $6.5 \pm 0.2$ \\
LPDE/PS 4 & 41,000 & $6.9 \pm 0.1$ \\
LPDE/PS $_{5}$ & 108,000 & $7.0 \pm 0.2$ \\
LPDE/PS $_{6}$ & 200,000 & $7.1 \pm 0.2$ \\
LPDE/PS $_{7}$ & 340,000 & $7.2 \pm 0.1$ \\
\hline
\end{tabular}

facial tension between low density polyethylene and polystyrene. A typical experiment to determine interfacial tension lasted between 6 to $10 \mathrm{~h}$ depending on the viscosity of the samples to be studied. The interfacial tension $\gamma(\mathrm{t})$ as calculated by the shape comparison could be fitted by an exponential decay. These results suggested the possibility of inferring the interfacial tension from transient data, thus shortening the duration of the experiment and eliminating the possibility of thermal degradation.

The interfacial tension between Low Density Polyethylene and Polystyrene was measured as a function of molecular weight of Polystyrene. It was shown that the interfacial tension increases as a function of molecular weight and levels off when the molecular weight of polystyrene reaches $30,000.00 \mathrm{~g} / \mathrm{mol}$

\section{Acknowledgments}

The authors would like to acknowledge a Fundação de Amparo a Pesquisa do Estado de São Paulo FAPESP (94/3351-6; 97/06071-2) for financial support and CAPES for the Master Scholarship of E. Y. Arashiro and Polisul for the GPC Analysis.

\section{References}

1. Wu, S. Polymer Eng. Sci., v. 27, n. 5, p. 335, 1987.

2.Xanthos, M.; Young, M.W.; Biesenberger, J.A. Polym. Eng. Sci., v. 30 n. 6, p. 335, 1990.

3. Sakai, T. Polymer, v. 6, p. 659, 1965.

4. Staicopulus, D.N. Journal Interface Sci, v. 17, p. 439, 1962.

5. Staicopulos, D.N. Journal Interface Sci, v. 18, p. 793, 1963.

6. Staicopulus, D.N. Journal Interface Sci., v. 23, p. 453, 1967.

7. Oda, Y.; Hata, T. Preprints, 267, Sixth Symposium on Adhesion and Adhesives, Osaha, Japan, p. 69, jun 1968.

8. Buttler, J.N.; Bloom, B.H. Surface Science, v. 4, p. 1, 1966.
9. Maze, C.; Burnet, G. Surface Science, v. 13, p. 451, 1969.

10. Maze, C.; Burnet, G. Surface Science, v. 24, p335, 1971.

11. Lau, W.Y.; Burns, C.M. Surface Science, v. 30, p. 483, 1972.

12. Patterson, H.T.; Hu, K.H.; Grindstaff, T.H. J. Polym. Sci., Part C, v. 34, p31, 1971.

13. Elmendorp, J.J.; de Vos G. Polym. Eng. Sci., v. 26, p. 415, 1986.

14. Verdier C. Topics in the Fluid Mechanics of Viscoelastic Liquids, PhD. Thesis, University of Minnesota, 1990.

15. Joseph, D.D.; Arney, M.S.; Gillberg, G.; Hu, H.; Hultman, D.; Verdier, C.; Vinagre, T.M.; Journal of Rheology, v. 36, n. 4, p. 623, 1992.

16. Hu, H.H.; Joseph, D.D. Journal of Colloid and Interface Science, v. 162, 331-339, 1994.

17. Roe, R.J. Journal of Colloid Interface Sci., v. 31, p. 228, 1969.

18. Wu, S. Journal of Colloid Interface Sci., v. 31, p. 153, 1969.

19. Wu, S. J. Phys Chem., v. 74, p. 632, 1970.

20. Koberstein, J. Report No ARO 22886.3 MS US Army Research Office Report "Characterization of Polymeric Surfaces and Interfaces, 1986.

21. Anastasiadis, S.H.; Chen, J.K.; Koberstein, J.T.; Sohn, J.E.; Emerson, J.A. Polym Eng and Sci. v. 26, p. 1410, 1986.

22. Anastasiadis, S.H.; Chen, J.K.; Kobertein, J.T.; Siegel, A F.; Sohn, J.E.; Emerson, J.A. J. Colloid Interface Sci, v. 119, p. 55, 1986.

23. Demarquette, N.R.; Kamal, M.R. Antec proceedings, p. $1907,1992$.

24. Demarquette, N.R.; Kamal, M.R. J. Polymer Engineering and Science, v. 34, n. 24, p. 1823-1833, 1994.

25. Demarquette, N.R.; Kamal, M.R. Polímeros: Ciência e Tecnologia, v. 7, n. 3, p. 63-70, 1997.

26. Kamal, M.R.; Lai Fook, R.; Demarquette, N.R. J. Polymer Engineering and Science, v. 34, n. 24, p. 1834-1839, 1994.

27. Runke, T.; Song, B. J Springer Ber Bunsenges Phys. Chem., v. 98, n. 3, p. 508-511, 1994.

28. Chappelear, D.G. Polymer Preprints, v. 5, p. 363, 1964.

29. Tomokita, S. Proc. R. Soc., London Ser., v. 150, p. 322 (1937).

31. Tomokita, S. Proc. Roy. Soc., v. 153, p. 302, 1936.

32. Luciani, A.; Champagne, M.F.; Utracki, L.A. Polym. Networks Blends, v. 6, n. 2, p. 51-62, 1996. 
33. Ellingson, P.C.; Strand, D.A.; Cohen, A.; Sammler, R.L.; Carriere, C.J. Macromolecules p. 1643-1647, 1994.

34. Carriere, C.J.; Cohen, A.; Arends, C.B. J. of Rheol, v. 33 n. 5, p. 681, 1989.

35. Carriere, C.J.; Cohen, A. J. of Rheol, v. 35, n. 2, p. 205, 1991.

36. Graebling, D.; Muller, R. Colloids and Surfaces, v. 55, p. 89, 1991.

37. Graebling, D.; Froelich, D.; Muller, R. Journal of Rheology, v. 33, n. 8, p. 1283, 1989.

38. Graebling, D.; Muller, R.; Palierne, J.F. Macromolecules, v. 26, p. 320, 1993.

39. Gramespacher, H.; Meissner, J. J Rheology, v. 36, n. 6, p. 1127, 1992.

40. Roe, R.J.; Bachetta, V.L.; Wong, P.M.G. J. Phys. Chem., v. 71, p. 4190, 1967.

41. Roe, R.J. J. Colloid Interface Sci., v. 31, p. 328, 1969.

42. Bashforth, S.; Addams, J.C. An Attempt to test the Theory of Capillary Action, Cambridge Unitersity Press and Deighton, Bell and Co, London, 1882.

43. Andreas, J.M.; Hauser, E.A.; Tucker, W.B. J. Physical Chemistry, v. 42, p. 1001, 1938.

44. Stauffer, C.E. J. Physical Chemistry, v. 69, n. 6, p. 1933, 1965.

45. Fordham, S. Proc. Roy. Soc of London, A 194, v. 1, 1948.

46. Adamson, A.W. Physical Chemistry of Surfaces, 2nd Edition, Wiley, interscience, New York, pp 9-41, 1967.

47.Wu, S. J. Macromol Sci., Revs Macromol. Chem., C10, p. 1, 1974.

48. Girault, H.H.; Schiffrin, D.J.; Smith, B.D.V. J. Electroanal Chem., v. 137, p. 207, 1982.

49. Girault, H.H.; Schiffrin, D.J.; Smith, B.D.V. J. Colloid Interfaces Sci., v. 93 p. 169, 1984.
50. Rotenberg, Y.; Bruvka, L.; Newman, A.W. J. Colloid Interface Sci., v. 93, p. 169, 1983.

51. Jimbo, I.; Cramb, AW. ISIJ International, v. 32, n. 1, p. 26-35,1992.

52. Cheng, P.; Li, D.; Boruvka, I.; Rotenberg, Y.; Newman, AW. J. of Colloid and Surfaces, v. 42, p. 151, 1990.

53. Skinner, F.K.; Rotenberg, Y.; Newman, AW. Journal of Colloid and Interface Science, v. 130, n. 1, 1989.

54. Ramos, A.L. de; Redner, R.A.; Cerro, R.L. Langmuir, v. 9 pp 3691-3694, 1993.

55. Lin, S-Y.; Hwang, H-Feng. Langmuir, v. 10 p. 47034709, 1994.

56. Siegel, AF. Biometrica, v. 69, p. 242, 1982.

57. Siegel, AF.; Benson, R.H. Biometrics, v. 38, p. 341, 1982.

58. Huh, H.; Reed, R.L. J. Colloid Interface Sci., v. 91, p. 472, 1983.

59. Matos, P.S.F. de; Demarquette, N.R. Anais do $12^{\circ}$ Congresso Brasileiro de Engenharia e Ciência dos Materiais, pp 1195-1198 Brasil, 1996.

60. Rodgers, P.A. Journal of Applied Polymer Science, v. 48, p. 1061-1080, 1993.

61. Fox, T.G. Jr., Flory, P.J. J. Appl Phys., v. 21 p. 581, 1950.

62. Zoller, P., Journal of Polymer Science: Polymer Physics Edition, v. 23, p. 1051-1056, 1979.

63. Hellwege, K.H.; Knappe, W.; Lehman, P. Kolloid Z.Z. Polym, v. 183, p. 110, 1962.

64. Kamal, M.R.; Demarquette, N.R.; Price, T.A.; LaiFook, R.A. Journal of Polymer Engineering and Sciences., v. 37, p. 813-825, 1997.

65. Welygan, D.G.; Burns, C.M. J. Adhesion, v. 14, p. 129, 1982. 